\title{
PENGEMBANGAN SISTEM INFORMASI PENJAMINAN MUTU (SIMANTU) LLDIKTI WILAYAH IV
}

\author{
Rangga Sanjaya ${ }^{1}$, Rissa Nurfitriana Handayani ${ }^{2}$ \\ Program Studi Sistem Informasi, Universitas Adhirajasa Reswara Sanjaya ${ }^{1,2}$ \\ rangga@ars.ac.id ${ }^{1}$,rissa@ars.ac.id ${ }^{2}$
}

\begin{abstract}
Abstrak
SPMI (Sistem Penjamin Mutu Internal) merupakan acuan bagi perguruan tinggi dalam menilai mutu kinerja dan penyelenggaraan pendidikan tinggi secara internal. SPMI penting untuk diperhatikan oleh perguruan tinggi agar mampu berkompetisi secara positif dengan perguruan tinggi lain di dalam maupun di luar negeri agar mampu meningkatkan pengelolaan dan penyelenggaraan pendidikan tinggi perguruan tinggi tersebut. Untuk dapat menilai ketercapaian masing-masing standar SPMI, DIKTI menyediakan aplikasi pemetaan perguruan tinggi untuk dapat melihat info grafik kinerja penyelenggaraan pendidikan tinggi di seluruh perguruan tinggi di Indonesia. Akan tetapi, dalam pelaksanaannya masih terdapat perguruan tinggi yang belum mengisi dan melengkapi dokumendokumen SPMI, sehingga hasil pemetaan yang dilakukan belum sepenuhnya mencerminkan kinerja perguruan tinggi secara faktual. Permasalahan yang sering dihadapi oleh perguruan tinggi dalam melaksanakan penilaian mutu internal adalah tidak terorganisirnya berkas dan dokumen administrasi SPMI. Hal tersebut dapat terjadi karena pengelola kampus tidak memiliki referensi yang cukup tentang bagaimana penyelenggaraan dan dokumentasi administrasi SPMI yang baik. Berdasarkan analisis permasalahan tersebut, dalam menunjang aktivitas pengelolaan dan penyelenggaraan perguruan tinggi, diperlukan adanya kolaborasi dan kerjasama diantara perguruan tinggi, yang difaslitatori oleh pemerintah dalam hal ini diwakili oleh LLDIKTI. Adanya aplikasi Sistem Penjaminan Mutu (SIMANTU) diharapkan dapat mengingatkan dan membantu LLDIKTI dan PT untuk mempersiapkan proses pendataan dalam kegiatan reakreditasi, melalui layanan portal informasi, pangkalan data (resource sharing), riwayat kegiatan, dan bilik konsultasi secara online. Kata kunci : SPMI, Sistem, Penjaminan Mutu
\end{abstract}

\begin{abstract}
SPMI (Internal Quality Assurance System) is a reference for universities in assessing the quality of performance and implementation of higher education internally. Higher education needs to pay attention to SPMI to be able to compete positively with other universities at home and abroad to be able to improve the management and implementation of the higher education. To be able to assess the achievement of each of the SPMI standards, DIKTI provides a university mapping application to be able to see graphical info on the performance of the implementation of higher education in all tertiary institutions in Indonesia. However, in its implementation there are still universities that have not filled in and completed the SPMI documents, so the results of the mapping that have been carried out do not fully reflect the performance of higher education. The problem that is often faced by universities in carrying out internal quality assessments is the disorganization of SPMI administrative files and documents. This can happen because the campus manager does not have sufficient references on how to conduct and good SPMI administration documentation. Based on the analysis of these problems, in supporting the management and implementation of higher education activities, collaboration and cooperation between universities is needed, which is facilitated by the government, in this case represented by LLDIKTI. The application of the Quality Assurance System (SIMANTU) is expected to be able to remind and help LLDIKTI and PT to prepare data collection processes in re-accreditation activities, through information portal services, database (resource sharing), activity history, and online consultation booths.
\end{abstract}

Keywords : SPMI, System, Quality Assurance

\section{PENDAHULUAN}

Penjaminan mutu perguruan tinggi adalah proses perencanaan, pemenuhan, pengendalian, dan pengembangan standar pendidikan tinggi secara konsisten dan berkelanjutan, sehingga pemangku kepentingan (stakeholders) internal dan eksternal perguruan tinggi, yaitu mahasiswa, dosen, karyawan, masyarakat, dunia usaha, asosiasi profesi, pemerintah dapat memperoleh kepuasan atas kinerja dan keluaran perguruan tinggi. Kegiatan penjaminan mutu ini merupakan perwujudan akuntabilitas dan transparansi pengelolaan perguruan tinggi. Sesuai Undang-undang Nomor 12 tahun 2012 tentang Pendidikan Tinggi, Sistem Penjaminan Mutu Pendidikan Tinggi (SPMPT) terdiri atas Sistem Penjaminan Mutu Internal (SPMI) dan Sistem Penjaminan Mutu Eksternal (SPME). SPMI dikembangkan oleh Perguruan Tinggi yang bersangkutan, sedangkan SPME dilakukan melalui akreditasi[4].

Sistem Penjaminan Mutu Internal (SPMI) di suatu perguruan tinggi merupakan kegiatan mandiri dari perguruan tinggi yang bersangkutan sehingga proses tersebut dirancang, dijalankan, dan dikendalikan sendiri oleh perguruan tinggi yang bersangkutan tanpa campur tangan dari pemerintah. Pemerintah membuat pedoman dalam pelaksanaan SMPI yang bertujuan untuk memberikan inspirasi tentang berbagai aspek yang pada umumnya terkandung dalam SPMI di suatu perguruan tinggi. Hal ini dilakukan karena setiap perguruan tinggi memiliki spesifikasi yang berlainan, dalam hal sejarah, visi dan misi, budaya organisasi, ukuran organisasi, struktur, sumber daya, dan pola kepemimpinan. Agar perguruan tinggi senantiasa mampu memenuhi tuntutan kebutuhan stakehoders yang terus berkembang, maka SPMI juga harus selalu disesuaikan dengan perkembangan tersebut secara berkelanjutan (continuous improvement) [5].

LLDIKTI Wilayah IV merupakan Lembaga yang bergerak pada bidang pelayanan Pendidikan Tinggi di Wilayah IV, salah satunya mendukung pelaksanaan penjaminan mutu pada pendidikan tinggi yang terdapat dilingkungan LLDIKTI Wilayah IV. Untuk dapat menilai ketercapaian masing-masing standar SPMI, DIKTI menyediakan aplikasi pemetaan 
perguruan tinggi untuk dapat melihat info grafik kinerja penyelenggaraan pendidikan tinggi di seluruh perguruan tinggi di Indonesia.

Akan tetapi, dalam pelaksanaannya masih terdapat perguruan tinggi yang belum mengisi dan melengkapi dokumendokumen SPMI, sehingga hasil pemetaan yang dilakukan belum sepenuhnya mencerminkan kinerja perguruan tinggi secara faktual. Permasalahan yang sering dihadapi oleh perguruan tinggi dalam melaksanakan penilaian mutu internal adalah tidak terorganisirnya berkas dan dokumen administrasi SPMI. Hal tersebut dapat terjadi karena pengelola kampus tidak memiliki referensi yang cukup tentang bagaimana penyelenggaraan dan dokumentasi administrasi SPMI yang baik.

Maka dari itu, penulis melakukan Pengembangan Sistem Informasi Penjaminan Mutu (SIMANTU) LLDIKTI Wilayah IV dengan menggunakan metode pengembangan sistem spiral.

\section{METODE PENELITIAN}

Metode pengembangan aplikasi yang digunakan menggunakan pendekatan model spiral. Model spiral merupakan penggabungan dari model prototyping dan model waterfall [2]. Model prototyping yang fokus pada penyajian atau presentasi kepada user dengan format input dan output kemudian perangkat lunak akan dievaluasi. Model waterfall yang fokus kepada proses pengembangan perangkat lunak yang sistematis atau berurutan.

Fungsi model spiral adalah untuk melakukan perubahan, penambahan dan pengembangan perangkat lunak dengan memaksimalkan aspek kecepatan dan ketepatan berdasarkan keinginan dan kebutuhan penggunanya.

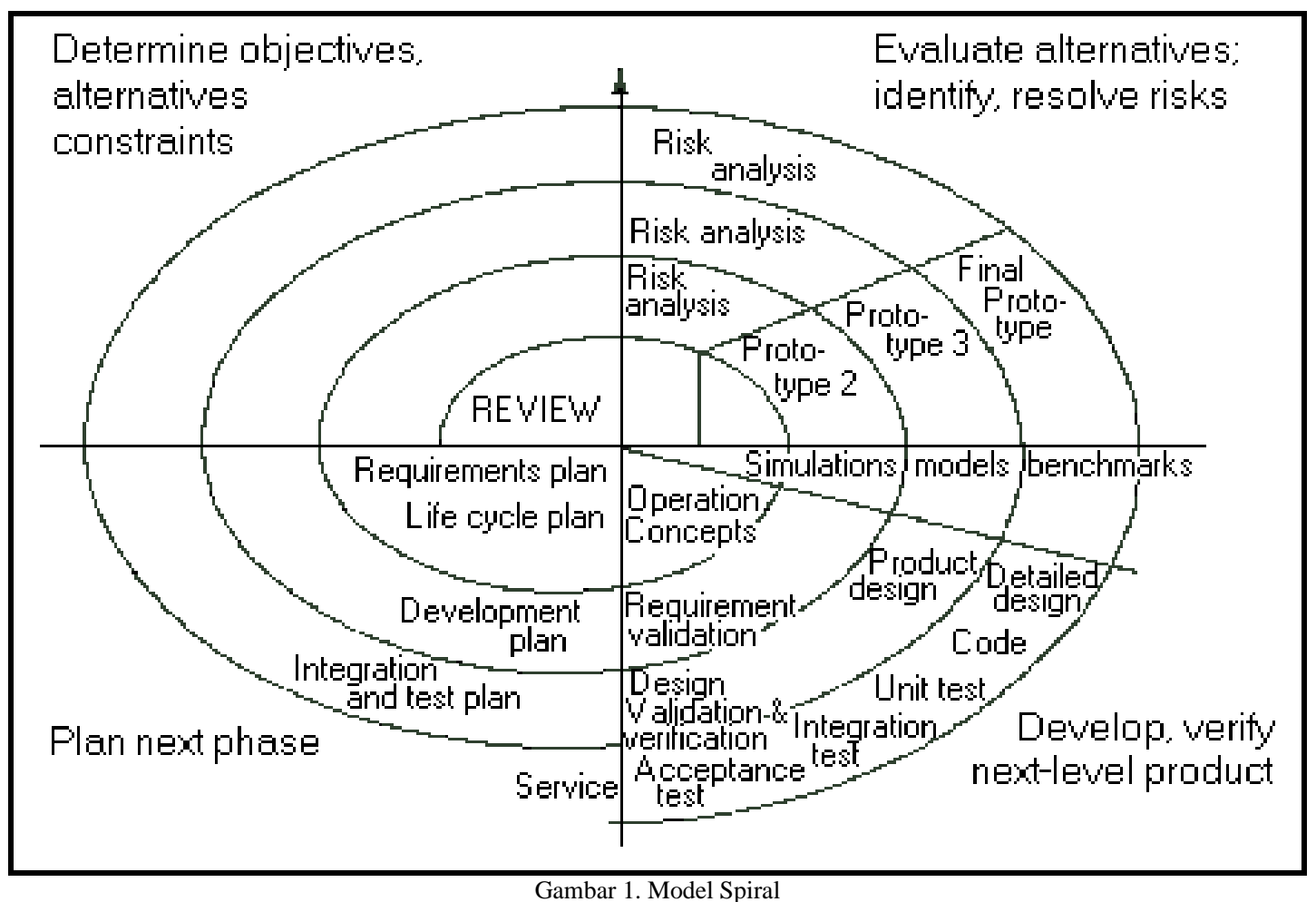

Sumber: [3]

Tahapan pengembangan aplikasi:

1. Tahap Liason

Tahap ini berhubungan dengan komunikasi antara pihak-pihak yang terlibat dalam pengembangan softaware dengan user. Tujuannya adalah memperbaiki dan mengembangan software sesuai kebutuhan dan keinginan user.

2. Tahap Planning

Tahap perencanaan meliputi estimasi batas waktu, pengaturan jadwal, identifikasi lingkungan kerja, sumbersumber informasi untuk melakukan iterasi. Hasil dari tahapan ini adalah dokumen spesifikasi kebutuhan sistem dan bisnis.

3. Tahap Analsis Risiko

Tahap analisis reisiko berfungsi untuk mengidentifikasi resiko yang berpotensi akan terjadi dan menghasilkan solusi alternatif secara teknis dan manajemen saat strategi mitigasi (upaya untuk mengurangi resiko bencana) direncanakan dan diselesaikan.

4. Tahapan Rekayasa

Pada tahap rekayasa, beberapa kegiatan ini yang akan dilakukan, yaitu:

a. Menguji, coding dan mengembangkan software

b. Membuat prototype

c. Mendesain dokumen 
d. Meringkas suatu pengujian software

5. Tahap Evaluasi

Pada tahap evaluasi, system analyst membutuhkan masukan dan tanggapan dari para user dalam mengevaluasi perangkat/produk yang diuji dan memastikan bahwa produk dibutuhkan sesuai ketentuan yang telah dibicarakan diawal dengan user. System analyst memastikan produk yang akan dihasilkan untuk menjawab persoalan bisnis mereka.

\section{HASIL DAN PEMBAHASAN}

\section{Hasil}

Berdasarkan hasil analisis kebutuhan sistem, diperoleh skema kebutuhan user terhadap sistem yang akan dikembangkan yang dapat dilihat pada diagram Use Case berikut:

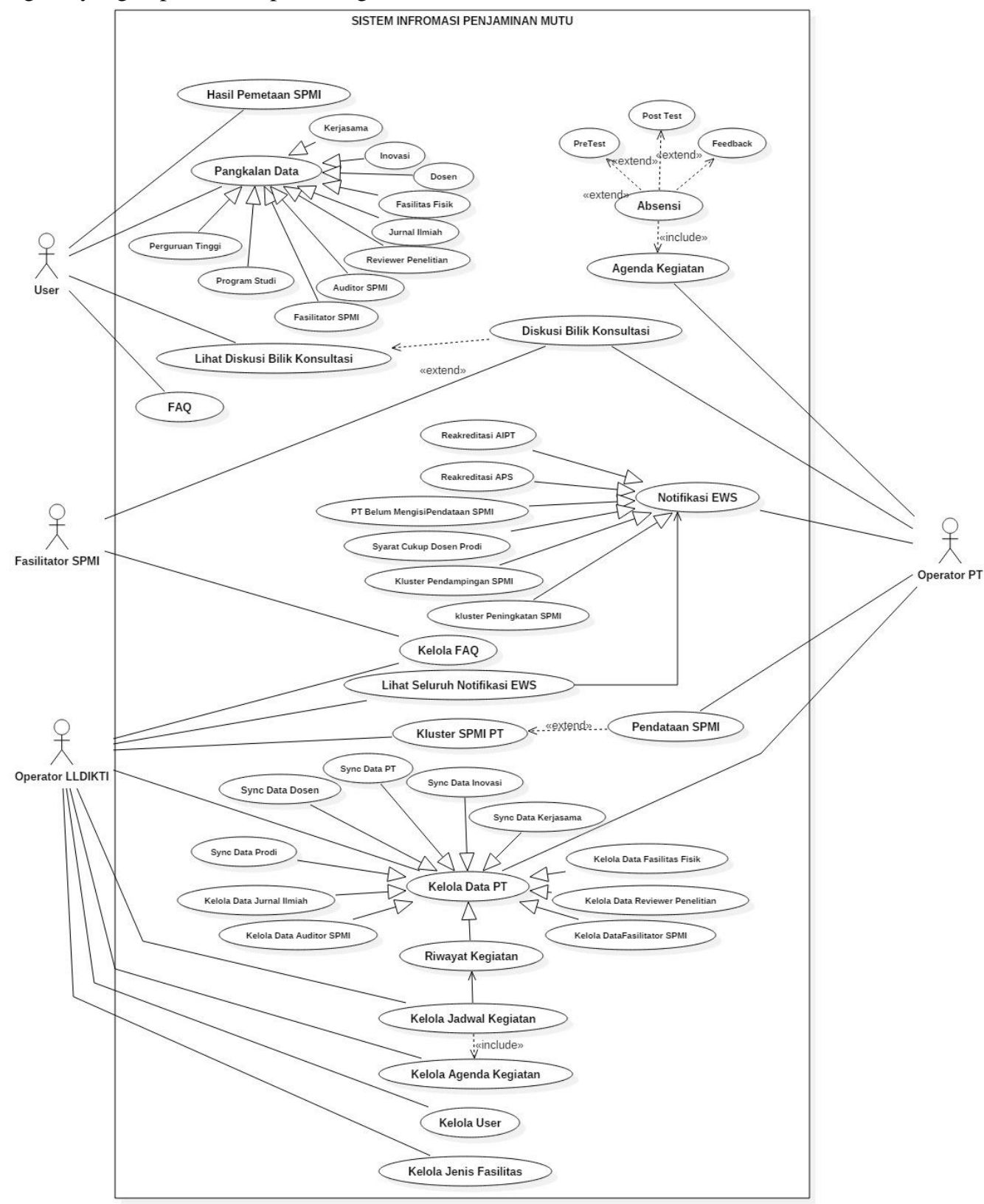

Gambar 2. Usecase Diagram SIMANTU

Fungsi dari Sistem Informasi Penjaminan Mutu (SIMANTU) terdiri atas:

a. Pemetaan SPMI; Pemetaan hasil pendataan implementasi SPMI (PPEPP) Perguruan Tinggi.

b. Pangkalan Data; Pangkalan Data resource sharing untuk peningkatan mutu perguruan tinggi.

c. Agenda; Agenda kegiatan SPMI untu pendampungan dan peningkatan mutu perguruan tinggi.

d. Bilik Konsultasi; Layanan konsultasi online untuk pendampingan dan peningkatan mutu perguruan tinggi. 
2. Pembahasan

Hasil dari pelaksanaan pengembangan sistem adalah tersedianya Sistem Informasi Penjaminan Mutu (SIMANTU) yang dapat dimanfaatkan oleh masyarakat, perguruan tinggi, internal LLDIKTI, dengan mengakses laman http://spmi.lldikti4.or.id.

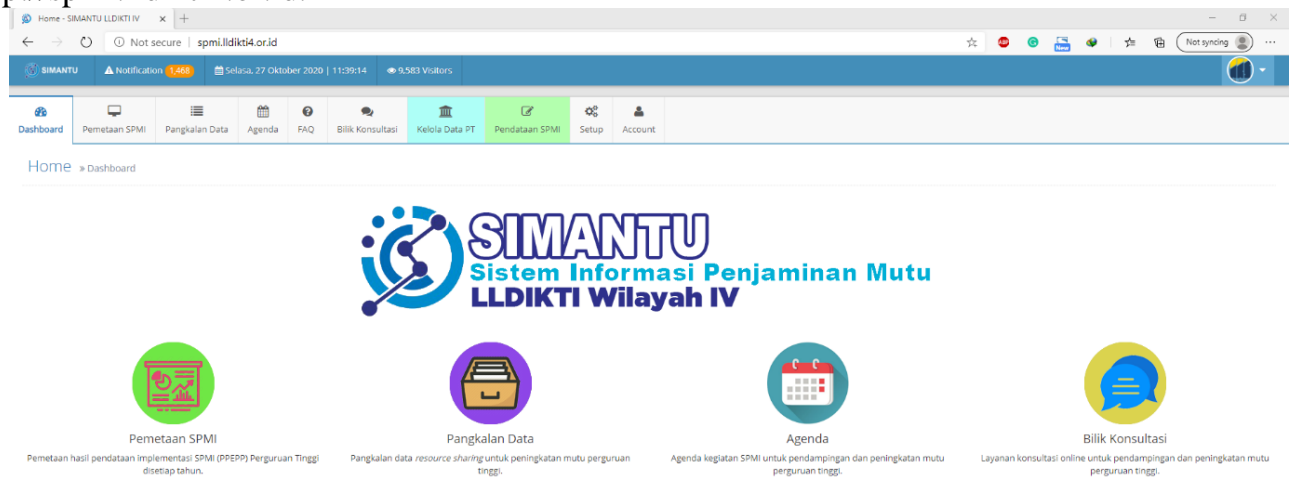

Gambar 3. Halaman SIMANTU

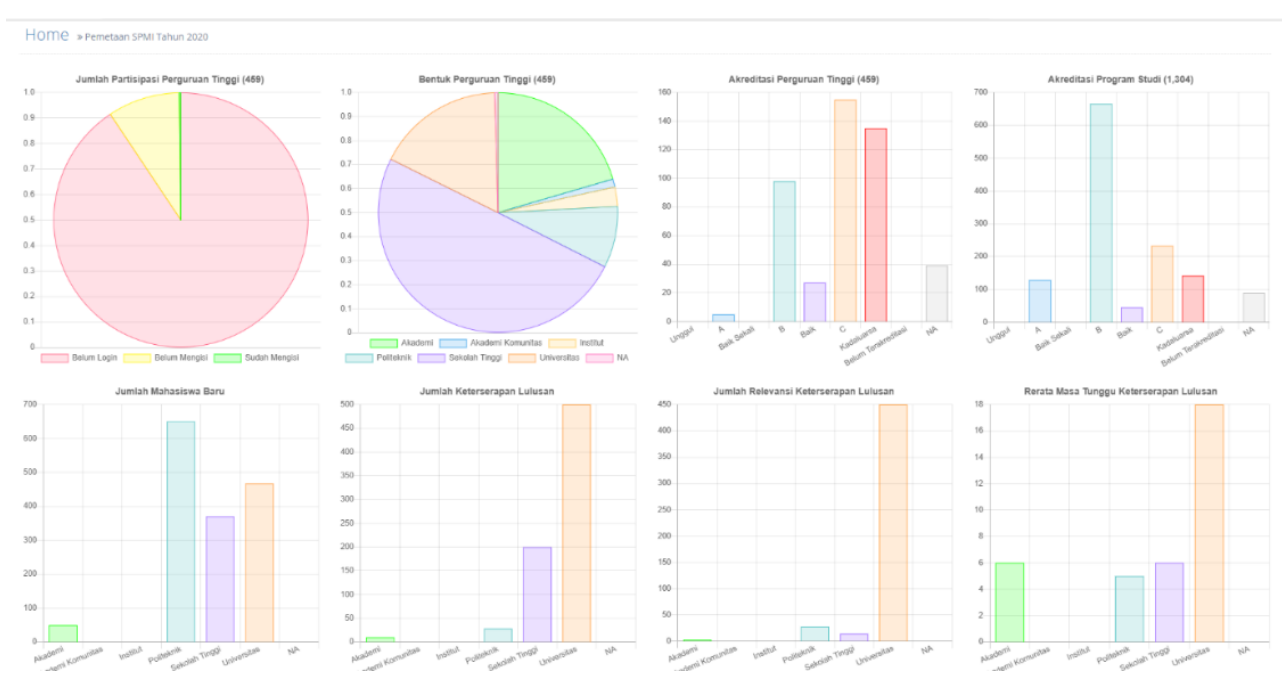

Gambar 4. Pemetaan SPMI

Pada Pemetaan SPMI yang terdapat pada Gambar 4. merupakan representasi data Perguruan Tinggi dilingkungan LLDIKTI Wilayah IV, yang mana hanya menampilkan data secara general, yang artinya tidak bisa dilihat secara spesifik mengenai identitas Perguruan Tinggi. 


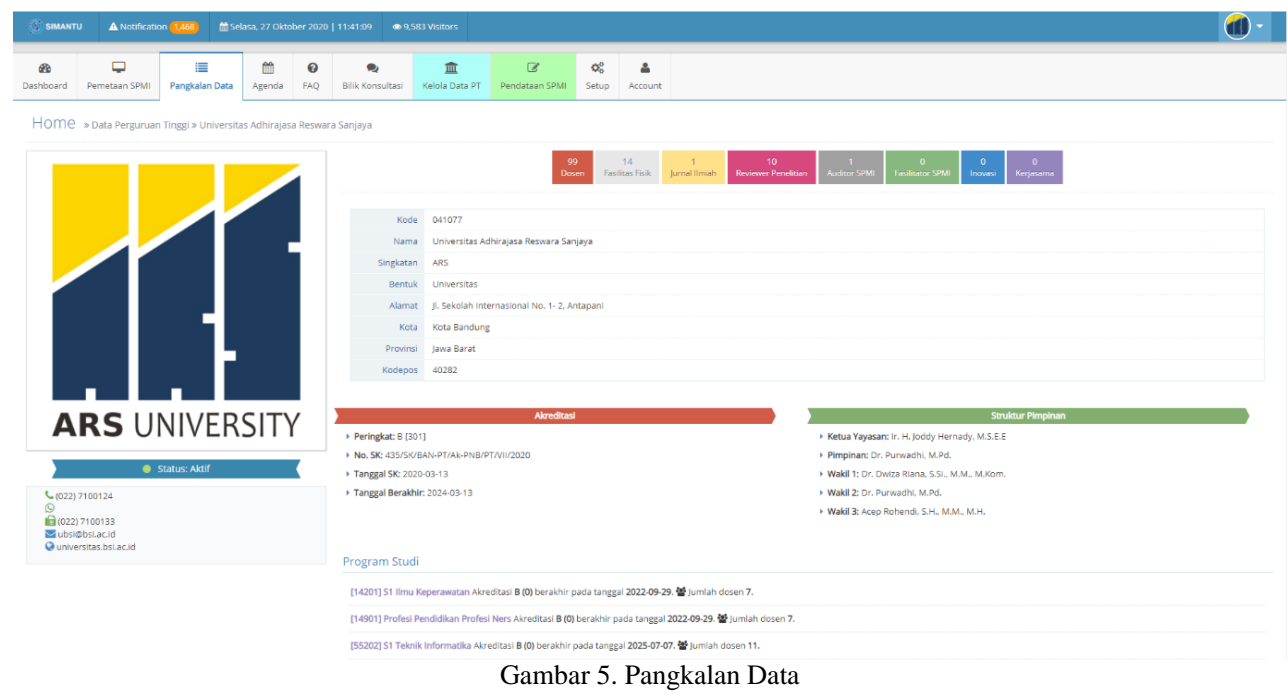

Pada Gambar 5. terdapat detail informasi perguruan tinggi secara detail mulai dari data dosen, fasilitas fisik, jurnal ilmiah, reviewer penelitian, auditor SPMI, Inovasi, dan kerja sama.

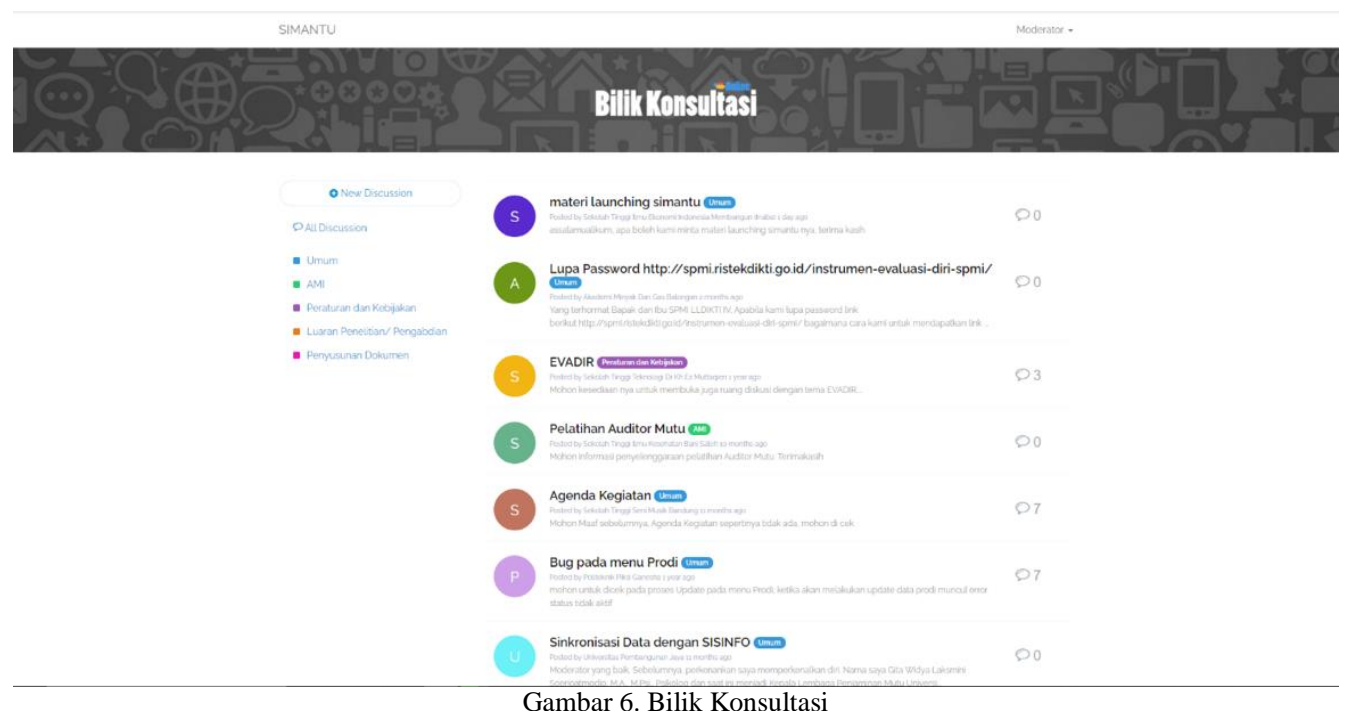

Pada menu bilik konsultasi (Gambar 6), perguruan tinggi dapat melakukan konsultasi kepada pengelola SIMANTU mengenai umum penggunaan sistem informasi, Audit mutu internal, bimtek, diseminasi, dan penyusunan dokumen SPMI.

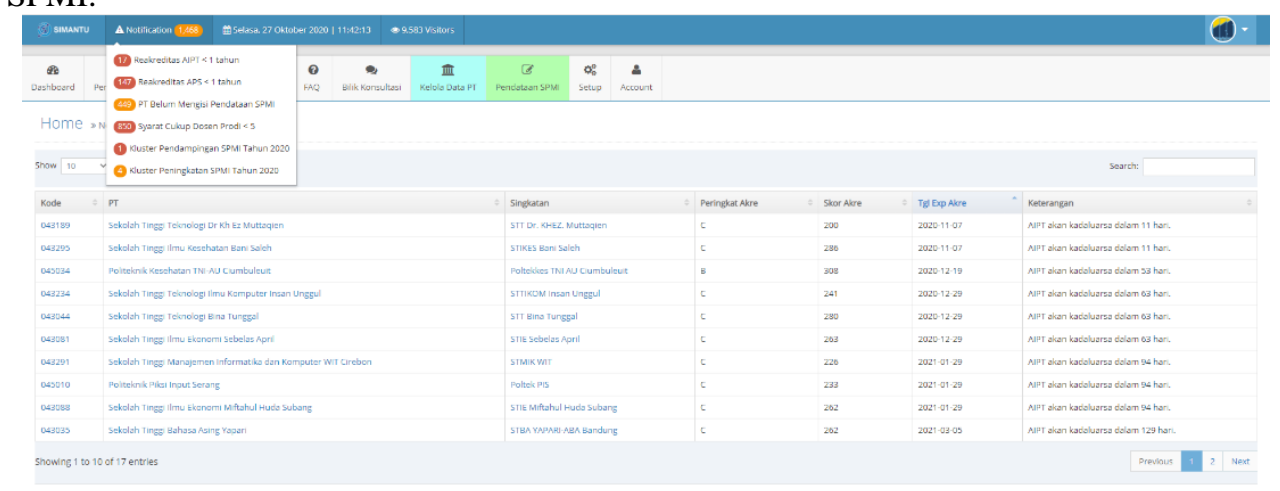


Setelah login terdapat fitur early warning system yang merupakan notifikasi untuk Reakreditasi AIPT dan APS yang masa kadaluarsanya kurang dari 1 tahun, notifikasi untuk PT yang belum mengsii pendataan SPMI, notifikasi syarat cukup dosen prodi < 5, dan notifikasi kluster peningkatan SPMI Tahun 2020.

\section{KESIMPULAN}

Dari pembahasan mengenai Sistem Informasi Penjaminan Mutu (SIMANTU) pada LLDIKTI Wilayah IV yang telah diuraikan, maka penulis menarik kesimpulan yaitu Sistem Informasi Penjaminan Mutu pada LLDIKTI Wilayah IV dapat mengefektifitaskan penjaminan mutu di perguruan tinggi. Efektivitas tercermin melalui termonitoringnya perguruan tinggi yang belum mengisi dan melengkapi dokumen-dokumen SPMI, dapat dilihat pula hasil pemetaan SPMI, dapat dilakukan konsultasi pada bilik konsultasi terkait SPMI dan sharing resource pangkalan data.

\section{REFERENSI}

[1] DIKTI. (2012). Sistem Penjaminan Mutu Pendidikan Tinggi. Indonesia: DIKTI

[2] Budi, D. S., Siswa, T. A., \& Abijono, H. (2016). Analisis Pemilihan Penerapan Proyek Metodologi Pengembangan Rekayasa Perangkat Lunak. TEKNIKA, 5(1), 24-31.

[3] Samsul, P. A., Sofiansyah, F., \& Maemun, S. (2019). Rancang Bangun Sistem Pengolahan Data Obat Menggunakan Model Spiral. MISI (Jurnal Manajemen Informatika \& Sistem Informasi, 36-42.

[4] Sulaiman, A., \& Wibowo, U. B. (2016). Implementasi Sistem Penjaminan Mutu Internal Sebagai Upaya Meningkatkan Mutu Pendidikan di Universitas Gajah Mada. Jurnal Akuntabilitas Manajemen Pendidikan, 4(1), 17-32.

[5] Wibowo, A., \& Azimah, A. (2016). Rancang Bangun Sistem Informasi Penjaminan Mutu Perguruan Tinggi Menggunakan Metode Throwaway Prototyping Development. Yogyakarta: STMIK AMIKOM. 